\title{
A Novel Biostimulant, Belonging to Protein Hydrolysates, Mitigates Abiotic Stress Effects on Maize Seedlings Grown in Hydroponics
}

\author{
Sara Trevisan ${ }^{1,2, *}$, Alessandro Manoli ${ }^{1}$ and Silvia Quaggiotti ${ }^{1}$ \\ 1 Department of Agronomy, Food, Natural Resources, Animals and Environment (DAFNAE), University of \\ Padova, viale dell'Università 16, 35020 Legnaro (PD), Italy; alessandro.manoli@hotmail.it (A.M.); \\ silvia.quaggiotti@unipd.it (S.Q.) \\ 2 Department of Land, Environment, Agriculture and Forestry (TESAF), University of Padova, \\ viale dell'Università 16, 35020 Legnaro (PD), Italy \\ * Correspondence: sara.trevisan@unipd.it; Tel.: +39-049-827-2913
}

Received: 28 November 2018; Accepted: 7 January 2019; Published: 9 January 2019

check for updates

\begin{abstract}
The main challenge to agriculture worldwide is feeding a rapidly growing human population, developing more sustainable agricultural practices that do not threaten human and ecosystem health. An innovative solution relies on the use of biostimulants, as a tool to enhance nutrient use efficiency and crop performances under sub-optimal conditions. In this work a novel biostimulant (APR®, ILSA S.p.A., Arzigano VI, Italy), belonging to the group of protein hydrolysates, was supplied to maize seedlings in hydroponic and its effects were assessed in control conditions and in the presence of three different kinds of stresses (hypoxia, salt and nutrient deficiency) and of their combination. Our results indicate that APR® is soluble and is able to influence root and shoot growth depending on its concentration. Furthermore, its effectiveness is clearly increased in condition of single or combination of abiotic stresses, thus confirming the previously hypothesised action of this substance as enhancer of the response to environmental adversities. Moreover, it also regulates the transcription of a set of genes involved in nitrate transport and ROS metabolism. Further work will be needed to try to transfer this basic knowledge in field experiments.
\end{abstract}

Keywords: Maize; biostimulant; root; stress; growth; gene expression

\section{Introduction}

Global population is expecting to increase to nine billion by 2050 [1] and agriculture will need to push crop production accordingly in order to sustain the greater demand for food. This is especially true in developing countries where high rates of population growth are associated to an increased urbanization, leading to changes in income levels and food preferences [2].

Moreover, climate change leading to abiotic pressures, such as rising droughts and other stresses correlated to higher temperature, are predicted to escalate in their severity and frequency $[3,4]$ thus seriously compromising crop productivity [5]. In fact, abiotic stress can reduce crop yields by more than $60 \%$ for major crops [6-8].

New crop protection solutions able to mitigate the main abiotic stresses represent a substantial opportunity to contribute to secure, higher and more stable yields. These innovations span across conventional breeding to biotechnology solutions [9] and also encompass new generations of agrochemicals [10]. The global crop protection market attained US $\$ 56.7$ billion in 2014. However, there are only limited solutions currently available to mitigate abiotic stresses. 
In recent years, the use of natural-derived biostimulants is proposed as an innovative solution to address the challenges of sustainable agriculture, by ensuring optimal nutrient uptake, crop yield, quality, and tolerance to abiotic stress [11].

An innovative technology with promising application potential entails the use of a particular class of biostimulants, the protein hydrolysates (PHs). PHs are mixtures of polypeptides, oligopeptides, and free amino acids derived by chemical or enzymatic hydrolysis of plant residues or animal connective tissues. The protein hydrolysates have been demonstrated to stimulate root growth and leaf biomass of several crops. Du Jardin [11] reviewed various effects resulting from the application of these compounds to crops and Van Oosten [12] reported several studies demonstrating the role of PHs in abiotic stress response.

Although the effects of protein hydrolysates on crop performance have been documented by several studies $[11,12]$ the scientific basis of their action has only partially been elucidated mainly due to the complex nature of these products [13]. However, the synthesis of the enzymatic hydrolysis of protein has been an advantageous, ecologically safe strategy to produce biostimulant [13], and more studies are needed to improve protein hydrolysates production techniques and to ensure a low- cost product for consumption and a high use efficiency [14].

In an earlier study we demonstrated a role for a new-synthetized PH (APR®, ILSA S.p.A.) in regulating the expression level of a thousand of genes in maize roots, and hypothesised that it could act by improving the plant responses to various environmental stresses [15]. Based on the results therein obtained $A P R{ }^{\circledR}$ has been proposed to enhance plant response to stress. However, this preliminary work has tested APR® on plants grown in not adverse conditions and APR® was applied directly to the soil mixture as solid granules. The chemical composition of this compound (identified also as AA309) is reported in subsequent study by Ertani et al. [16] which also performed Fourier transform infrared (FTIR). The chemical analysis revealed the presence of several amino acids, as lysine, phenylalanine, glycine, aspartate, and isoleucine. The present substance is still under study and its dossier is expected to be definitively completed by the next three months.

Due to the economic importance of maize and the limitations in fertilizer applications imposed during its development, it is important to dissect the effects of the biostimulant on the initial growth of maize seedlings, at both morphological and transcriptomic levels. For this reason, most of the present works on APR® are focused on its effects on this species.

Our previous work [15] suggested that APR® is at least in part soluble and reach root through the soil solution. Furthermore, it seems to act as a stress tolerance enhancer, by modulating the transcription of a wide set of genes involved in ROS detoxification and nutrient acquisition. However, no results on its effects in abiotic stress conditions were gained until now. Our various results with this species indicate that maize is able to sense and rapidly respond to nutritional fluctuations already after hours or minutes of treatment [17-20]. Therefore in the present work, we tried to deepen the effects of APR®, supplied in in hydroponic, in affecting the early response of maize seedlings to abiotic stresses. To this aim we first aimed to assess the APR® activity by measuring its effects on plant growth and identified the optimal concentration to be used in further experiments. Subsequently, to study the effectiveness of APR $®$ as an enhancer of plant tolerance to abiotic stress we grown maize seedlings in the presence of different single and combined abiotic stresses and supplying them with APR®. Our results on root and shoot growth and on the expression profiles of a number of previously identified genes [16] provide further evidence of the APR ${ }^{\circledR}$ biostimulant activity, which early induce root to elongate and affects gene expression, especially increased in conditions of environmental limitations.

\section{Materials and Methods}

\subsection{Maize Seedlings Growth}

Seeds of maize (Zea mays L.), inbred line B73, were washed in distilled water and germinated on wet filter paper at $25{ }^{\circ} \mathrm{C}$ in the dark. After three days, maize seedlings were transferred in 
a controlled environmental chamber in $500 \mathrm{ml}$ tanks containing a nutrient medium which was constantly aerated and composed as previously described in Quaggiotti [21] and changed every two days. Plants were grown in a growth chamber with an 8-h photoperiod under $200 \mu \mathrm{mol} \mathrm{m}{ }^{-2} \mathrm{~s}^{-1}$ of photosynthetically active radiation (PAR; daylight and warm white 1:1, LF-40W) at day/night temperatures of $21 / 18{ }^{\circ} \mathrm{C}$ [21]. The $\mathrm{pH}$ of the medium was checked during the growth period and remained at a stable level of around $\mathrm{pH}$ 6.5. For analysis of RNA root samples were frozen in liquid nitrogen and stored at $-80^{\circ} \mathrm{C}$.

\subsection{Set up of the Novel Biostimulant Concentration to be Supplied to Stressed Maize Plants}

Maize seedlings were hydroponically grown for three days in distilled water containing different APR ${ }^{\circledR}$ concentrations, resulting in a variable nitrogen content which ranged from $1 \%$ to $10 \%$ of the amount of nitrogen supplied by the Hoagland-modified nutrient solution previously described. $A P R \circledR$ granules were added to tanks $2 \mathrm{~h}$ before putting plants into the water and constantly stirred until all product has dissolved.

This series of concentrations was selected basing on their relative content of nitrogen, paying attention to keep it to a sub-nutritional level. To evaluate their effects the root length, root and shoot fresh weight were measured. Data are expressed as the average of three replicates $(n=10) \pm$ standard error. For statistical analysis, we compared morphological data derived from the corresponding four different $\mathrm{APR}{ }^{\circledR}$ concentrations with those of control plants.

\subsection{Stress Application and Morphological Analyses}

To try to assess the effect of $A P R \circledast$ on maize tolerance to abiotic stress three single stress (hypoxia, salt and nutrient starvation) and two stress combination (hypoxia plus nutrient starvation, salt plus nutrient starvation) were imposed to seedlings for three days. Comparisons were made among non-stressed and stressed plants, which were then compared with plants supplied also with $5 \%$ of APR®,

Hypoxic stress conditions were achieved by not bubbling air through the liquid solution for the entire experiment. For salt stress, a $25 \mathrm{mM} \mathrm{NaCl}$ concentration, which corresponds to mild salt stress in maize was employed [22-24]. For nutritional stress, seedlings were grown in distilled water only. Each treatment was performed in three biological replicates.

After 3 days, roots and shoots of control and APR® treated plants were harvested. For the morphological analyses, 10 randomly selected seedlings for biological replicate were used.

The remaining plants were immediately frozen in liquid nitrogen and kept at $-80{ }^{\circ} \mathrm{C}$ for subsequent RNA extraction.

\subsection{RNA Extraction, and cDNA Synthesis}

Total RNA was extracted from root tissues using TRIzol reagent (Invitrogen, Carlsbad, CA, USA) as previously described by Trevisan et al., [17]. DNAse digestion was performed whit RQ1 RNAse-free DNAse (Promega, Madison, WI, USA) on an aliquot of total RNA as described by Trevisan et al. [17]. RNA was quantified using a Nanodrop 1000 (Thermo Scientific, Nanodrop Products, Wilmington, DE, USA) and its quality further validated by sterile agarose gel electrophoresis. cDNA was synthesized from $500 \mathrm{ng}$ of total RNA mixed with $1 \mu \mathrm{l}$ of $10 \mu \mathrm{M}$ oligo-dT, as described by Manoli et al. [25].

\subsection{Real Time $q P C R$}

Relative quantification of transcripts by RT-qPCR was performed in a StepOne Real-Time PCR System (Applied Biosystems, Foster City, CA, USA). Reactions were performed using SYBR Green chemistry (Applied Biosystems fast SYBR Green Master Mix, Thermo Fisher Scientific, Waltham, MA, USA), following the manufacturer's instructions. Reverse-transcribed RNA ( $2.5 \mathrm{ng}$ ) was used as template in each reaction as indicated by Manoli [26]. Three technical replicates were performed for each thesis using the conditions described by Trevisan et al. [17]. Melting-curve analysis confirmed 
the absence of multiple products and primer dimers. Data were exported and analysed according to the method of Livak and Schmittgen [27] and MIQE guidelines [28]. Only transcripts showing amplification with quantification cycle $(\mathrm{Cq})<35$ were selected for subsequent gene expression analysis.

All of the primers used in these assays are listed in Table S1.

\subsection{Data Analysis}

The expression levels of the analysed genes were normalized via comparison to the expression of the internal reference gene (MEP, membrane proteinPB1A10.07c, primers: forward 5'-TGTACTCGGCAATGCTCTTG-3' and reverse 5'-TTTGATGCTCCAGGCTTACC-3'), as the reference gene [25]. The standard error was calculated from the standard deviation and the variation coefficient of the reference gene and of the genes under assessment.

For statistical analysis, we compared stress condition plants with its own control. Data represent means \pm SD of 3 independent experiments performed in triplicate. For the gene expression levels analyses and the choice of the APR® concentration, multiple comparison statistics were calculated using the software RStudio (https:/ / www.rstudio.com/) Version 1.1.453. differences among samples were verified with either ANOVA (normality and homogeneous variances) or Welch's one-way ANOVA (normality and non-homogeneous variances) followed by post hoc LSD or Waller-Duncan test, respectively, and with Kruskal-Wallis (non-normality and homogeneous variances) or Friedman test (non-normality and nonhomogeneous variances). For all statistics a $p$-value threshold of 0.05 was adopted. For the subsequent growth analyses, one-way ANOVA test followed by Tukey's HSD test was performed. Asterisks indicate significant differences $\left({ }^{*}: p<0.05 ;{ }^{* *}: p<0.02\right)$. One-way ANOVA, Tukey's HSD test.

\section{Results}

\subsection{Choice of the Novel Biostimulant Concentration to be Used for Subsequent Treatments in Hydroponics}

In order to assess the most effective APR ${ }^{\circ}$ concentration four different APR ${ }^{\circ}$ concentrations $(1 \%, 2 \%, 5 \%$ and $10 \%)$ were used and their effects were observed in comparison to those measured for seedlings grown in distilled water for the same period (Ctrl) (Figure 1).

APR ${ }^{\circledR}$ application induced a significant increment of root length when supplied in hydroponic at a concentration of $5 \%$ The $10 \%$ dose showed a reduction on root length respect to the $5 \%$.

In the case of root and shoot weight no statistically significant differences were observed (Figure 1B,C). According to these data, we decided to use a $5 \%$ concentration of APR ${ }^{\circledR}$ for all subsequent analyses. 

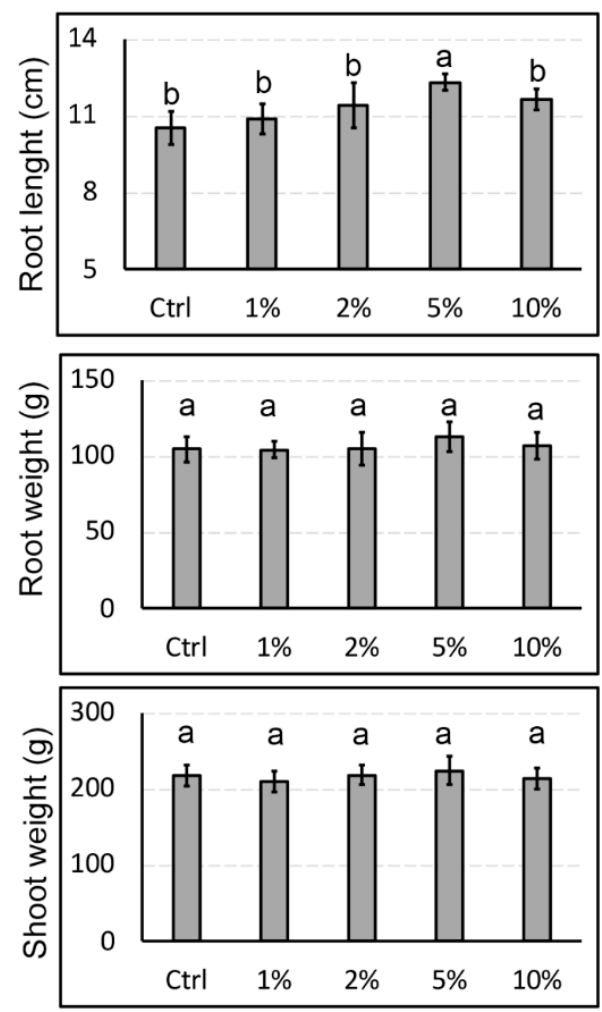

Figure 1. Effects of different $A P R \circledR$ concentrations on the physiological growth parameters of Zea mays L. seedlings. The graphs represent the root length, the root weight and the shoot weight of maize seedlings hydroponically grown for three days at increasing concentrations of APR®. The values represented in the graphs were calculated from three independent experiments $(n=10)$ and represent the mean \pm the standard error. Significantly different values $(p<0.05)$ are evidenced by different letters (One-way Anova, LSD post-hoc test).

\subsection{Biostimulant Effects on Root Length in the Presence of Different Stress}

When maize seedlings were subjected to hypoxic stress $(\mathrm{H})$ the root length showed values $12 \%$ lower if compared to control plants (Figure 2). However, when APR® was supplied to the nutrient solution a significant increase of root elongation was measured, with values $10 \%$ higher than those observed for hypoxic plants and similar to those noticed for control plants.

A similar pattern was observed when plants were subjected to salt stress (S), which triggered a visible reduction in primary root length. However, the provision of APR® triggered a significant increment of root length, thus restoring the phenotype of control plants.

Also in the case of nutrient deprivation $(\mathrm{N})$ the supply of APR ${ }^{\circledR}$ significantly induced the primary root to elongate.

The positive effect of $A P R \circledast$ provision was even more marked in the case of combined stress. In fact, when hypoxia was associated to nutritional stress $(\mathrm{N} / \mathrm{H})$ primary root length was visibly in comparison to the control, but the presence of APR® markedly and significantly restrained this negative effect leading to a phenotype comparable with that observed in not stressed plants. A positive influence of the biostimulant was observed also in the case of the combination between salt stress and nutritional stress $(\mathrm{N} / \mathrm{S})$, which inhibited the primary root growth, but the provision of APR $®$ led to a root elongation $40 \%$ higher than that measured for stressed plants.

The provision of APR ${ }^{\circledR}$ to control plants did not induce significant effects on root elongation. 


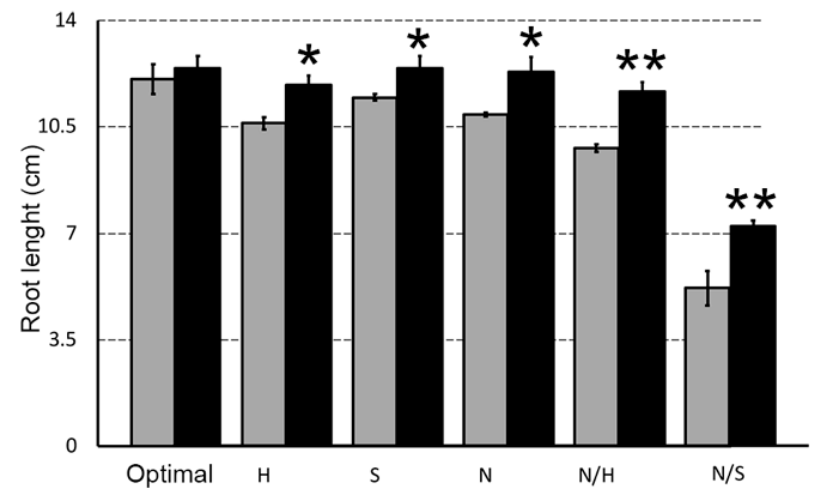

Figure 2. APR ${ }^{\circledR}$ counteracts the negative effects of single and combined abiotic stress on root length. Maize seedlings were subjected for 3 days to several abiotic stresses in absence (grey bars) or in presence (black bars) of 5\% APR®. The applied single stresses were: hypoxic stress (H), salt stress (S), nutritional stress $(\mathrm{N})$. The single stresses were combined as: hypoxic stress plus nutritional stress $(\mathrm{N} / \mathrm{H})$ and salt stress plus nutritional stress $(\mathrm{N} / \mathrm{S})$. The values of root length $(\mathrm{cm})$ are represented in the graphs (mean $\pm \mathrm{SE}$ ) and were calculated from three independent experiments $(n=10)$. Significantly different values are evidenced by * ${ }^{*}: p<0.05 ;{ }^{* *}: p<0.02$; One-way ANOVA, Tukey's HSD test).

\subsection{Biostimulant Effects on Root and Shoot Weight in the Presence of Different Stress}

To verify if the increments observed in terms of primary root length were associated to an increase of total root weight, these parameters was measured in the same conditions described above (Figure 3). When maize seedlings were subjected singularly to the three different stresses (hypoxia, salt, nutritional deficiency) or to the hypoxia and nutritional deficiency $(\mathrm{N} / \mathrm{H})$ combination the root weight did not evidence significant differences in comparison to the control plants nor in response to the biostimulant. On the contrary, a significant increase of root weight in response to APR® provision was measured when plants were subjected to the combination of nutritional and salt stress (N/S).

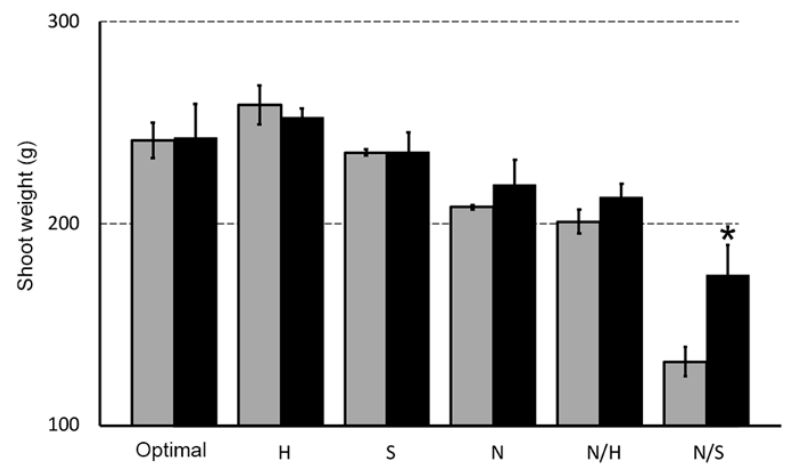

Figure 3. Effects of APR® on root weight in response to different single and combined abiotic stresses. Maize seedlings were subjected for 3 days to several abiotic stresses in absence (grey bars) or in presence (black bars) of $5 \%$ APR $囚$. The applied single stresses were: hypoxic stress $(\mathrm{H})$, salt stress $(\mathrm{S})$, nutritional stress $(\mathrm{N})$. The single stresses were combined as: hypoxic stress plus nutritional stress $(\mathrm{N} / \mathrm{H})$ and salt stress plus nutritional stress (N/S). The values of root weight $(\mathrm{g})$ are represented in the graphs (mean $\pm \mathrm{SE}$ ) and were calculated from three independent experiments $(n=10)$. Significantly different values are evidenced by * $(*: p<0.05 ; * *: p<0.02$; One-way ANOVA, Tukey's HSD test).

As far as the shoot weight was concerned (Figure 4) no differences were observed in response to stress, nor providing APR $®$, except in the case of the contemporary presence of nutritional starvation and salt stress (N/S). In fact, the co-presence of these two stresses highly inhibited shoot weight

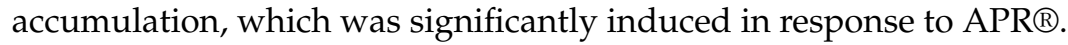




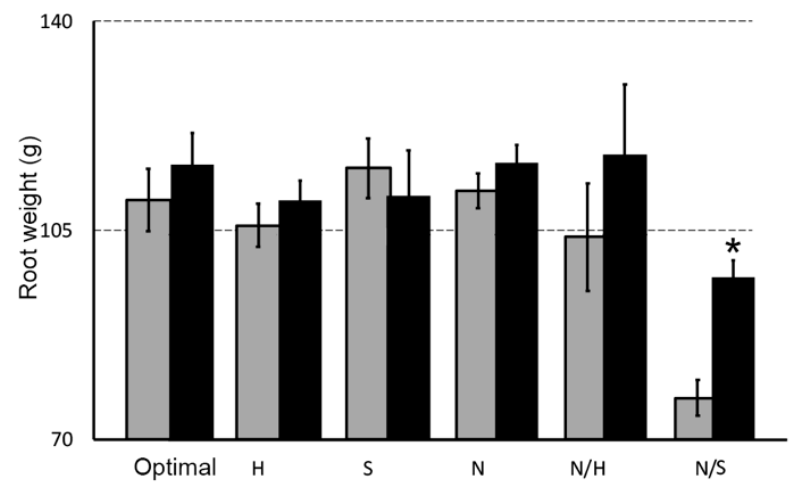

Figure 4. Effects of APR® on shoot weight in response to different single and combined abiotic stresses. Maize seedlings were subjected for 3 days to several abiotic stresses in absence (grey bars) or in presence (black bars) of 5\% APR®. The applied single stresses were: hypoxic stress $(\mathrm{H})$, salt stress $(\mathrm{S})$, nutritional stress $(\mathrm{N})$. The single stresses were combined as: hypoxic stress plus nutritional stress $(\mathrm{N} / \mathrm{H})$ and salt stress plus nutritional stress $(\mathrm{N} / \mathrm{S})$. The values of root weight $(\mathrm{g})$ are represented in the graphs (mean $\pm \mathrm{SE}$ ) and were calculated from three independent experiments $(n=10)$. Significantly different values are evidenced by ${ }^{*}: p<0.05 ;{ }^{* *}: p<0.02$; One-way ANOVA, Tukey's HSD test).

\subsection{Biostimulant Regulation of Gene Expression}

A number of genes belonging to the group of nitrate transporters and of ROS metabolism were selected basing both on previous results (Trevisan et al. 2017 [20]) and on their putative physiological role (Table 1).

Table 1. Description and classification of the targets genes studied in QPCR expression analysis. The expression levels of genes belonging to nitrate transport system (HATS and LATS) and related to reactive oxygen species (ROS) generation and homeostasis were analyzed.

\begin{tabular}{|c|c|c|c|}
\hline & Maize GDB Accession ID & Code & Description \\
\hline \multirow{5}{*}{ HATS } & Zm00001d054057 & ZmNRT2.1 & High affinity nitrate transporter \\
\hline & Zm00001d054060 & ZmNRT2.2 & High affinity nitrate transporter \\
\hline & Zm00001d014976 & ZmNRT2.3 & High affinity nitrate transporter \\
\hline & Zm00001d017095 & ZmNAR2.1 & High affinity nitrate transporter \\
\hline & Zm00001d003287 & ZmNAR2.2 & High affinity nitrate transporter \\
\hline \multirow{5}{*}{ LATS } & Zm00001d024587 & ZmNRT1.1 & Nitrate transporter \\
\hline & Zm00001d029932 & ZmNRT1a & Dual-affinity nitrate transporter \\
\hline & Zm00001d036941 & ZmNRT1b & Nitrate transporter \\
\hline & Zm00001d017666 & ZmNRT1.5 & Nitrate transporter \\
\hline & Zm00001d007785 & ZmNRT & Nitrate and chloride transporter \\
\hline \multirow{6}{*}{ ROS } & Zm00001d042961 & ZmRbohA & Respiratory burst oxidase protein $\mathrm{A}$ \\
\hline & Zm00001d043543 & ZmRbohB & Respiratory burst oxidase protein $B$ \\
\hline & Zm00001d038762 & ZmRbohC & Respiratory burst oxidase protein $\mathrm{C}$ \\
\hline & Zm00001d052653 & ZmRbohD & Respiratory burst oxidase protein $\mathrm{D}$ \\
\hline & Zm00001d031908 & $\mathrm{ZmSOD}$ & Superoxide dismutase [Cu-Zn] \\
\hline & $\mathrm{Zm00001d027511}$ & ZmCAT2 & Catalase 2 \\
\hline
\end{tabular}

The nitrate transporters genes include five genes encoding putative high affinity components of nitrate transport (three ZmNRT2 and two ZmNAR2 genes respectively, Figure 5) and five encoding members of the NRT1 gene family which is involved in the low affinity nitrate transport system (Figure 6). As far as the ROS genes were concerned this group comprise four genes encoding 
NADPHoxidase ( $\mathrm{ZmRBOH} a, b, c$ and $d$ ), one encoding Catalase2 (ZmCAT2) and a gene encoding a $\mathrm{Cu}$-Zn Superoxide dismutase ( $\mathrm{ZmSOD})$.

The specific effects of the biostimulant on the different groups of genes in conditions of different stress are discussed below.
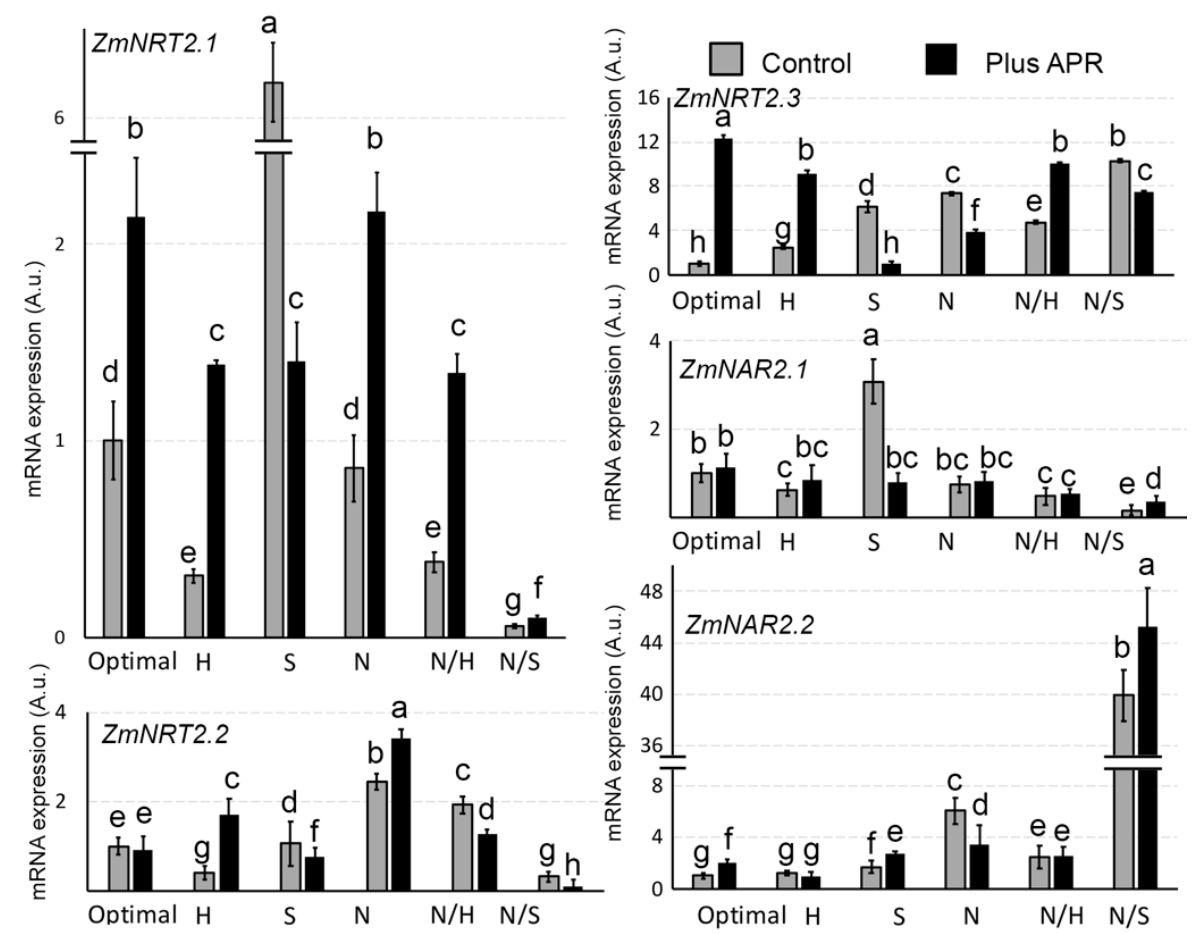

Figure 5. The gene expression patterns of nitrate transporters belonging to the High Affinity Transport Systems (HATS) maize gene family in response to different single and combined abiotic stress are influenced by the presence of APR®. Q-PCR analyses were carried out on root of stressed $(\mathrm{H}, \mathrm{S}$, $\mathrm{N}, \mathrm{N} / \mathrm{H}, \mathrm{N} / \mathrm{S}$ ) or unstressed (optimal) maize seedlings grown for 3 days in absence (grey bars) or in presence (black bars) of $5 \%$ APR®. Relative mRNA level represents data normalized to control $($ Optimal $=1)$. The values shown are means of three biological replicates \pm SE. Significantly different values $(p<0.05)$ are evidenced by different letters (One-way Anova, LSD post-hoc test). 


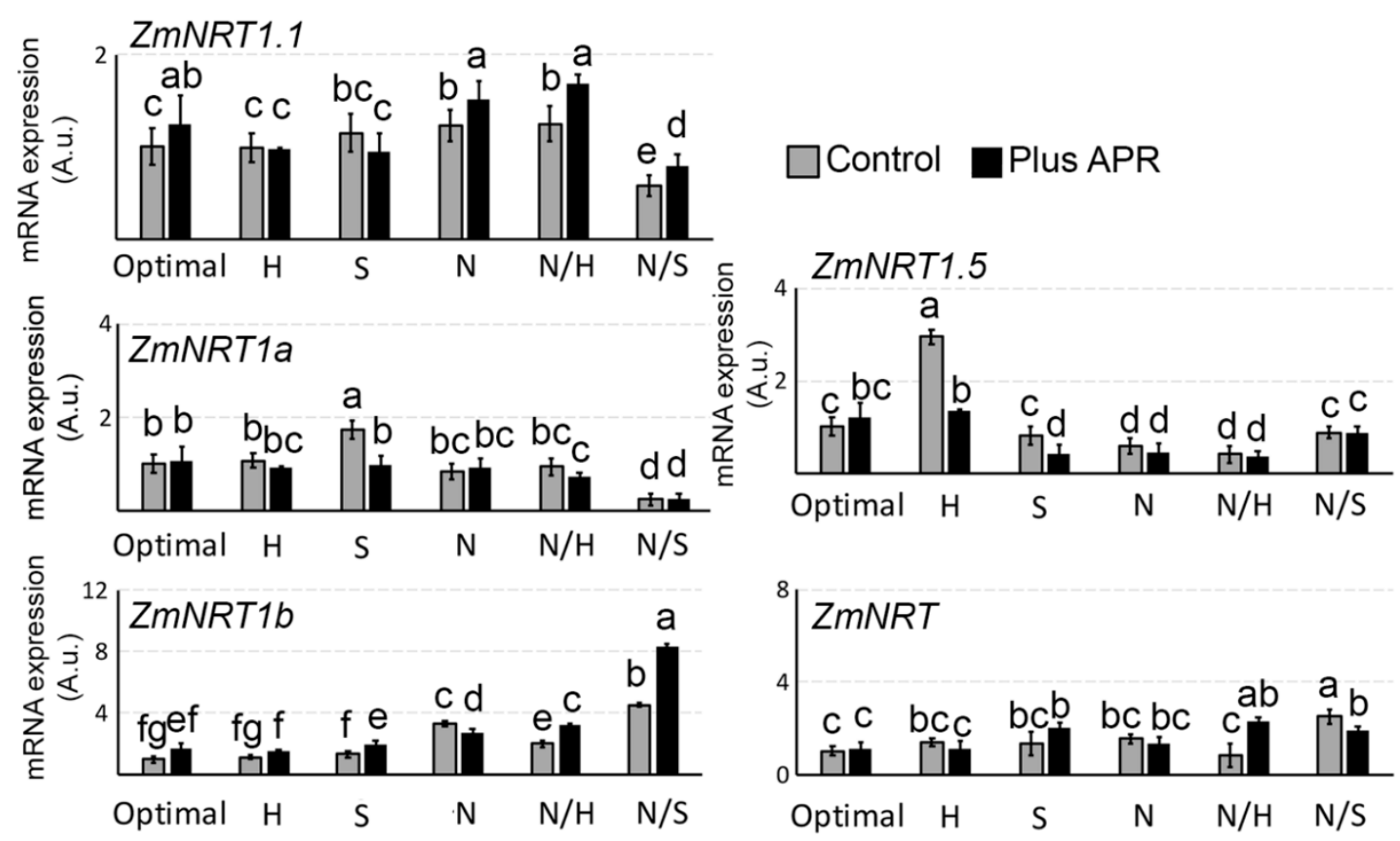

Figure 6. The gene expression patterns of nitrate transporters belonging to the Low Affinity Transport Systems (LATS) maize gene family in response to different single and combined abiotic stress are influenced by the presence of APR ${ }^{\circledR}$. Q-PCR analyses were carried out on root of stressed (H, S, $\mathrm{N}, \mathrm{N} / \mathrm{H}, \mathrm{N} / \mathrm{S}$ ) or unstressed (optimal) maize seedlings grown for 3 days in absence (grey bars) or in presence (black bars) of 5\% APR®. Relative mRNA level represents data normalized to control (Optimal $=1$ ). The values shown are means of three biological replicates $\pm \mathrm{SE}$. Significantly different values $(p<0.05)$ are evidenced by different letters (One-way Anova, LSD post-hoc test).

\subsection{Biostimulant Effects on ZmNRT2 Genes Expression}

In general, the most striking effects of $A P R \circledR$ on gene transcription regulation in roots were observed in conditions of stress and for the group of genes operating in the high affinity nitrate transport system. In hypoxic conditions, the expression of ZmNRT2.1, ZmNRT2.2, ZmNRT2.3 and ZmNAR2.1 was down-regulated in response, but when APR® was supplied a significant increase of their transcription was observed (Figure 5).

The same group of genes were, on the contrary, up-regulated in response to salt stress, but the provision of $\mathrm{APR}{ }^{\circledR}$ significantly counteracted this effect, leading to restore the phenotype of un-stressed roots (Figure 5).

In the case of nutrient starvation, instead, unique behaviours were observed for each gene belonging to the high affinity nitrate transport group, with ZmNRT2.1 and ZmNRT2.2 being significantly up-regulated and, ZmNRT2.3 and ZmNAR2.2, being down-regulated as a consequence of APR® provision (Figure 5).

When seedlings were subjected to a combination of hypoxia and nutritional stress the transcription of ZmNRT2.1 and ZmNRT2.3 were clearly induced, whilst ZmNRT2.2 expression was down-regulated (Figure 5).

The co-presence of nutritional deficiency and salt triggered for all these genes significant dysregulation of transcription. However, APR® provision restrained this outcome for all of them, except for ZmNAR2.3 which was further induced by APR®. Except for this situation, the transcription of ZmNAR2.3 evidenced always minor changes in response to both stress conditions and APR ${ }^{\circledR}$ provision (Figure 5 ).

In the case of ZmNRT2.1, ZmNRT2.3 and ZmNAR2.2 a significant up-regulation of expression was noticed also in control condition (un-stressed plants), 


\subsection{Biostimulant Effects on NRT1 Genes Expression}

The transcription of genes implicated in the low affinity transport apparatus was less affected by both stress conditions and $A P R \circledast$, if compared to that of high affinity constituents. Hypoxic conditions induced an increase of the transcription of ZmNRT1.5 which was significantly counteracted when APR ${ }^{\circledR}$ was provided to the solution (Figure 6). Salt stress triggered an increased transcription of ZmNRT1a, which was then inhibited by APR®. The supply of APR® to nutritional starved roots triggered significant change of transcription for ZmNRT1.1, ZmNRT1b, ZmNRT (Figure 6).

APR ${ }^{\circledR}$ significantly affected the expression of these genes, except for ZmNRT1.5 in plants subjected to a combination of hypoxia and nutrient deficiency (Figure 6). When the combination of nutritional starvation and salt was applied to plants and APR® was supplied to roots significant changes of transcription were noticed, except for ZmNRT1a and ZmNRT1.5 (Figure 6).

\subsection{Biostimulant Effects on ROS Genes Expression}

As observed for NRT1 genes also in this case no regulation of expression was noticed upon APR ${ }^{\circledR}$ supply on unstressed seedlings (Figure 7). A more appreciable effect of the biostimulant was observed upon stress conditions. As reported in Figure $7 \mathrm{ZmSOD1A}$ transcription was induced upon $\mathrm{APR} \circledast$ treatment in hypoxia, nutritional deficiency, association between hypoxia and nutritional stress and also in the case of nutritional and salt combined stresses. On the contrary no evident alterations of expression were measured for $Z m C A T 2$ neither in response to stress nor in response to $A P R \circledR$ (Figure 7). As far as $Z m R b o h$ genes were concerned their expression was regulated by APR® in response to single and combined stress, even if to a lower extent in compared to ZmSOD1A (Figure 7).

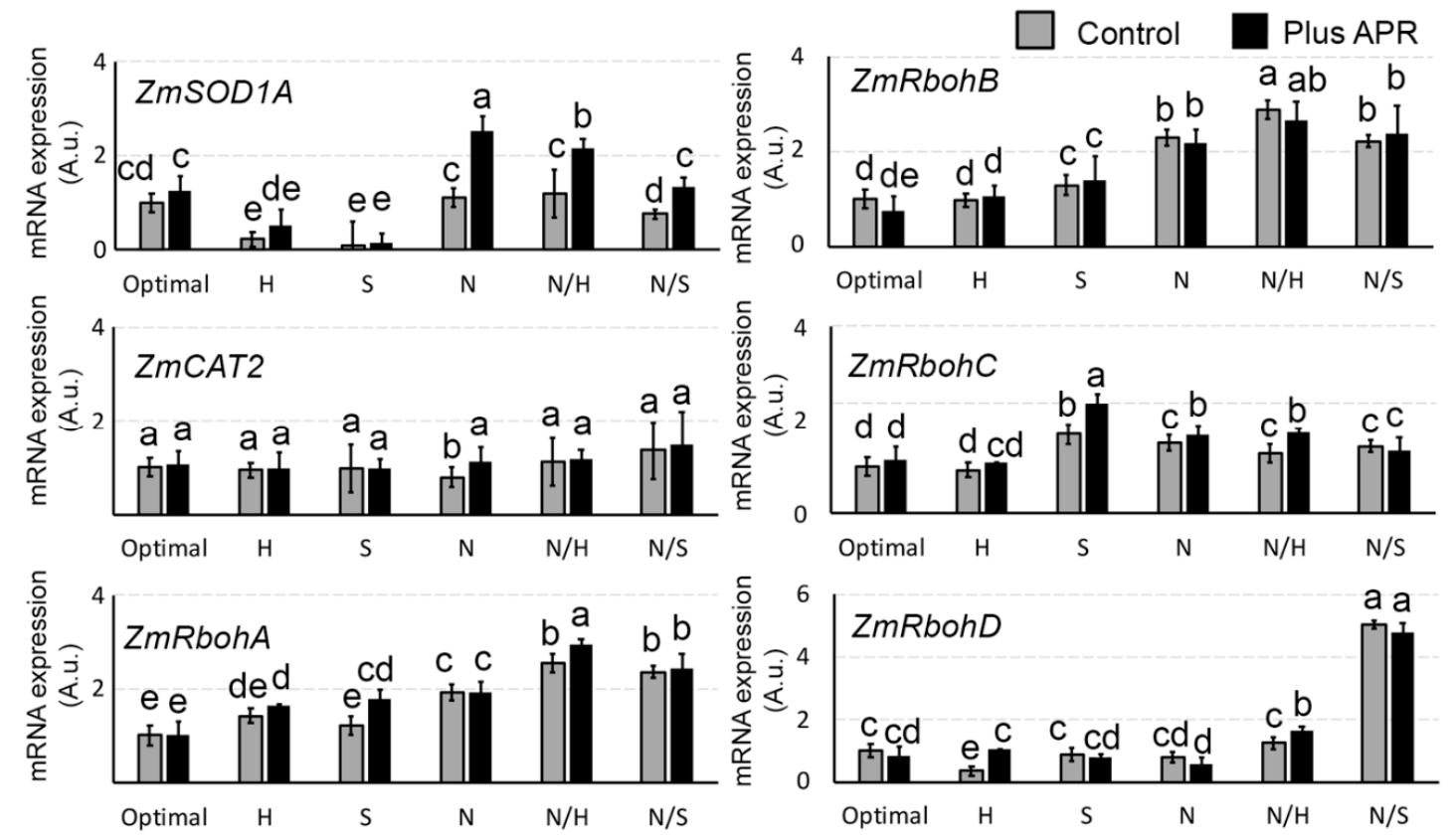

Figure 7. The expression patterns of ROS-related genes in response to different single and combined abiotic stress are influenced by the presence of APR $®$. Q-PCR analyses were carried out on root of stressed (H, S, N, N/H, N/S) or unstressed (optimal) maize seedlings grown for 3 days in absence (grey bars) or in presence (black bars) of $5 \%$ APR®. Relative mRNA level represents data normalized to control (Optimal $=1)$. The values shown are means of three biological replicates $\pm \mathrm{SE}$. Significantly different values $(p<0.05)$ are evidenced by different letters (One-way Anova, LSD post-hoc test).

\section{Discussion}

Protein hydrolysates are defined as 'mixtures of polypeptides, oligopeptides and amino acids that are manufactured from protein sources using partial hydrolysis' [29]. Their positive effects on 
plant performance have encouraged an increasing interest for their use in a more sustainable model of agriculture [30], this leading likewise to a promising solution to the issue of waste disposal [29-33].

Recently a trascriptomic approach was used to study the molecular effects of a collagen derived protein thermal hydrolysate (APR ${ }^{\circledR}$ ) produced by Ilsa S.p.A. (Arzignano) on maize roots grown in a solid medium and supplied with localized patches of APR ${ }^{\circledR}[16]$. Globally the results allowed to recognize a complex APR® action on physiological pathways involved in the stress response and in nutrient acquisition, which seems likely to prime the plant to better tolerate environmental adversities. In the present work the effectiveness of this biostimulant in modulating and improving the maize tolerance to environmental constrains was tested by growing seedlings in different specific abiotic stress conditions and supplying APR ${ }^{\circledR}$ in hydroponics. Overall our data indicate that this compound is soluble in an aqueous solution, suggesting the idea that in soil it can likely move toward roots through mass flow and diffusion and not only being intercepted as a nutrient patch by root growth.

To choose the most effective APR® concentration on plant development, the root and shoot growth were assessed by determining their fresh weights and the root length upon four different concentrations, chosen on the basis of our previous results [16]. The most accepted scientific definition for biostimulants is: "a plant biostimulant is any substance or microorganism applied to plants with the aim to enhance nutrition efficiency, abiotic stress tolerance and/or crop quality traits, regardless of its nutrients content", as reported in du Jardin [11]. According to this, we tested different solutions containing four APR ${ }^{\circledR}$ amounts to which corresponded four different $\mathrm{N}$ sub-nutritional concentrations ( $1 \%, 2 \%, 5 \%$ and $10 \%$ respect to the control Hoagland solution). The most remarkable effect was observed for primary root growth which was stimulated in response to APR® concentrations ranging from 1 to $5 \%$ and then inhibited in the presence of a $10 \%$ concentration. Detrimental effects of high concentrations of various protein hydrolysates have been observed also by other authors depending on the crop, the typology of biostimulant and the conditions of application [34].

Furthermore, the present results showed that $\mathrm{APR}{ }^{\circledR}$ affects root elongation and gene expression in particular when seedlings were subjected to different kind of stresses, confirming the hypothesis put forward by Trevisan and co-authors [16] and thus supporting the suggestion that biostimulants could act as plant protectors able to improve stress tolerance [11], likely by activating the main signalling pathways underlying the response to adverse conditions. Other reports showed that protein hydrolysates modulate plant growth, increase yield and alleviate the impact of abiotic stress on crops $[35,36]$. The present results, together with those of Trevisan [16] further suggest that this action could involve the molecular regulation of definite genes.

In general, the combination of two or more abiotic stresses has a detrimental impact on crops that is not predictable from that of each of the stresses composing the combination if applied individually. In recent years stress combination has been acknowledged as a novel state of stress and as a major cause of crop loss worldwide [37-39]. For this reason, we decided to assess the APR® potentiality in alleviating stress impact also in condition of stress combination.

As expected the most striking effect of $A P R \AA$ on growth re-establishment in conditions of abiotic stress was observed for roots, which are the main target for hypoxia, salt and nutrient deprivation stresses. The plastic control of the root development throughout time and in response to endogenous and exogenous stimuli allows plants to efficiently adapt to environmental constraints [40,41]. Root apex is highly responsive to external stimuli and rapidly adjusts its growth to efficiently adapt to environmental constraints and resources availability $[19,26,42-47]$. In this work a clear induction of primary root growth upon APR® treatment was noticed in all the conditions examined, with the most prominent effect in the case of combination of stresses. The simultaneous presence of nutritional deficiency and salt stress led to the most relevant arrest of growth which was, however, at least partially prevented when plants were supplied with APR®. In this case a similar behaviour was observed also in shoot, leading to hypothesise that APR® is able to act also as a systemic clue, firstly perceived by root cells, but likewise triggering a phenotypic response in shoots. This systemic action could be the outcome of the already hypothesised function of APR ${ }^{\circledR}$ as activator of the stress tolerance [16]. 
Moreover, it could depend on the protein hydrolysates ability to interfere with hormonal signaling, due to the presence of bioactive peptides (for a review Colla [48]) or aminoacids, as confirmed by the chemical composition of this same compound described by Ertani et al., [15]. Recent transcriptomic findings which highlighted the regulation of hormonal key elements by APR® [16] and a different study aimed to characterize the metabolomic regulation by biostimulant [49] reinforces this hypothesis.

Protein hydrolysates seem to improve nutrient uptake through modifications of root architecture (density, length and number of lateral roots), as well as through complexation of nutrients by peptides and amino acids, and also enhancing microbial activity thus increasing the nutrient availability in soil [11,34]. Moreover, a recent paper [50]. demonstrated that protein hydrolysates modulate plant growth and the expression of key genes in $\mathrm{N}$ assimilation (including Nitrate and ammonia transporters) in tomato. However only few information has been obtained on protein hydrolysates regulation of nutrient transport system. To better decipher this last aspect, a number of previously identified by Trevisan et al. [16] target genes involved in nitrate transport were chosen as markers for evaluating the transcriptional effects of the treatment.

Our results evidenced a marked regulation of the transcription of genes encoding members of the high affinity nitrate transport system (HATS, NRT2 and NAR genes), which was particularly relevant in condition of abiotic stresses. The impact of APR $®$ supply on the molecular regulation of the Low Affinity Transport System was less evident, leading to suppose that the provision of APR® mainly affects the functioning of the uptake of nitrate in the range of the High Affinity System, which are recognised to play a crucial role in determining the global Nitrogen Use Efficiency (NUE) in condition of limited nutritional inputs [51].

Trevisan et al. [16] also hypothesised that APR® could activate tolerance pathways, by mimicking the plant responses to environmental stresses, thus priming them against unfavourable conditions through the regulation of enzymes involved in the pathway governing the response to oxidative stress. To deepen this hypothesis the analyses of the expression of six genes involved in ROS signalling and defence was assessed, in condition of stress and in the presence of APR $囚$. Only SOD1A showed a clear regulation in response to $A P R{ }^{\circledR}$ which almost in all the conditions analysed induced its expression, whilst for the other five genes no significant differences were evidenced upon APR® supply.

Superoxide dismutases (SODs) are key enzymes functioning as the first line of antioxidant defence by virtue of the ability to catalyse the enzymatic dismutation of superoxide to $\mathrm{H}_{2} \mathrm{O}_{2}$ [52]. The present result reinforces the hypothesis that APR might preventively prepare plants to oxidative stresses, by enhancing their own detoxifying tools.

In conclusion, basing on the more acknowledged definition of biostimulant [11], our results confirm the effectiveness of $A P R \AA$ as an enhancer of abiotic stress tolerance, thus allowing to definitely include it among the category of biostimulants (Figure 8). Moreover, present results strengthen the importance of root as a target for APR®, which has been proven to affect both root development and transcription of genes involved in Nitrogen Use Efficiency and ROS detoxification. Both these actions could lead to an improved tolerance to abiotic stresses, as nutritional starvation, salt and hypoxia which take place in the soil environment.

These preliminary knowledges should be in the future transferred in field experiment to further assess the APR® usefulness in agriculture. 


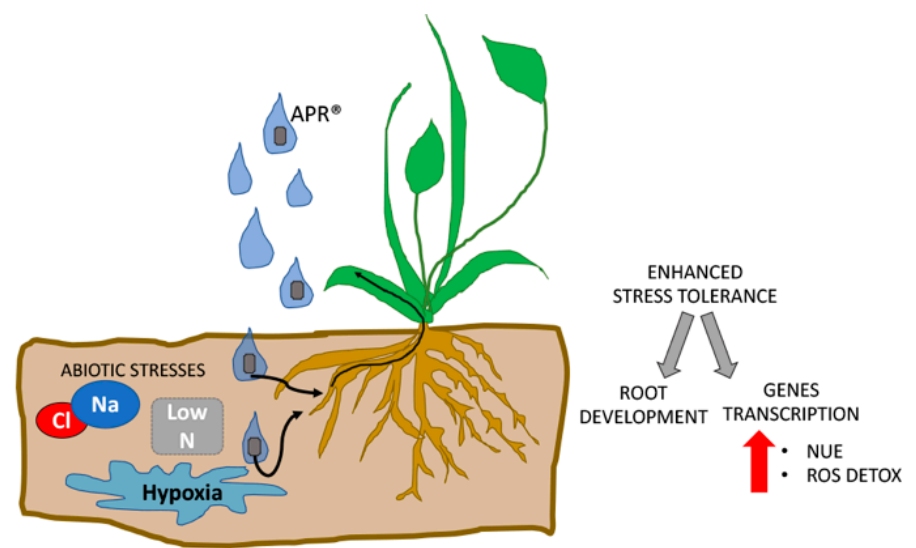

Figure 8. Direct and indirect effects of APR on plant growth in response to single and combined abiotic stresses. APR is perceived by the roots and modulates the root length by balancing the expression of genes involved in nitrate transport and ROS detoxification. APR could be systemically transported to the upper part of the plant, inducing a growth response in the shoot.

Supplementary Materials: The following are available online at http:/ /www.mdpi.com/2073-4395/9/1/28/s1, Table S1: List of primers used in gene expression analysis.

Author Contributions: Conceptualization, S.Q. and A.M.; Methodology, S.T. and A.M.; Data Curation, S.T.; Writing-Original Draft Preparation, S.Q. and S. T.; Writing-Review \& Editing, S.Q. and S.T.; Supervision, S.Q.; Project Administration, S.Q.; Funding Acquisition, S.Q.

Funding: This work has been supported by ILSA S.p.A and by University of Padova (DOR 2017). S.T. was financed by a grant from ILSA S.p.A.

Acknowledgments: The authors are thankful to F. Favaron (Department of Land, Environment, Agriculture and Forestry, University of Padova) for the constructive comments in improving this study. Special thanks to C. Franceschi (ILSA S.p.A.) and C. Manoli (ILSA S.p.A.) who assisted in this work.

Conflicts of Interest: The authors declare no conflict of interest. The funders had no role in the design of the study; in the collection, analyses, or interpretation of data; in the writing of the manuscript; or in the decision to publish the results.

\section{References}

1. UN Department of Economic and Social Affairs. Population Division. 2017. World Population Prospects: The 2017 Revision. Key Findings and Advance Tables. Working Paper No. ESA/P/WP/248. Available online: https: / www.compassion.com/multimedia/world-population-prospects.pdf (accessed on 7 January 2019).

2. UNPD Department of Economic and Social Affairs. World Urbanization Prospects: The 2014 Revision. United Nations Development Programme; 2014: Food and Agriculture Organization of the United Nations (FAO). 2014. The Future of the Food and Agriculture: Trends and Challenges. FAO: Rome, Italy, 2017. Available online: http:/ / www.fao.org/publications/fofa/en/ (accessed on 2 July 2018).

3. Rosenzweig, C.; Elliott, J.; Deryng, D.; Ruane, A.C.; Müller, C.; Arneth, A.; Boote, K.J.; Folberth, C.; Glotter, M.; Khabarov, N.; et al. Assessing agricultural risks of climate change in the 21st century in a global gridded crop model intercomparison. Proc. Natl. Acad. Sci. USA 2014, 111, 3268-3273. [CrossRef] [PubMed]

4. Myers, S. Planetary health: Protecting human health on a rapidly changing planet. Lancet 2017, 390, 860-2868. [CrossRef]

5. Coleman-Derr, D.; Tringe, S.G. Building the crops of tomorrow: Advantages of symbiont-based approaches to improving abiotic stress tolerance. Front. Microbiol. 2014, 5, 283. [CrossRef] [PubMed]

6. Bray, E.A.; Bailey-Serres, J.; Weretilnyk, E. Responses to abiotic stresses. In Biochemistry and Molecular Biology of Plants; Buchanan, B.B., Gruissem, W., Jones, R.L., Eds.; American Society of Plant Physiologists: Rockville, MD, USA, 2000; pp. 1158-1203.

7. Grover, A.; Kapoor, A.; Lakshmi, O.S.; Agarwal, S.; Sahi, C.; Agarwal, K.; Agarwal, M.; Dubey, H. Understanding molecular alphabets of the plant abiotic stress responses. Curr. Sci. 2001, 80, 206-216. 
8. Singhal, P.; Jan, A.T.; Azam, M.; Haq, Q.M.R. Plant abiotic stress: A prospective strategy of exploiting promoters as alternative to overcome the escalating burden. Front. Life Sci. 2016, 1, 52-63. [CrossRef]

9. Lamaoui, M.; Jemo, M.; Datla, R.; Bekkaoui, F. Heat and Drought Stresses in Crops and Approaches for Their Mitigation. Front. Chem. 2018, 19, 6-26. [CrossRef]

10. Antoniou, C.; Savvides, A.; Christou, A.; Fotopoulos, V. Unravelling chemical priming machinery in plants: The role of reactive oxygen-nitrogen-sulfur species in abiotic stress tolerance enhancement. Curr. Opin. Biotechnol. 2016, 33, 101-107. [CrossRef] [PubMed]

11. du Jardin, P. Plant biostimulants: Definition; concept; main categories and regulation. Sci. Hortic. 2015, 196, 3-14. [CrossRef]

12. Van Oosten, M.J.; Pepe, O.; De Pascale, S.; Silletti, S.; Maggio, A. The role of biostimulants and bioeffectors as alleviators of abiotic stress in crop plants. Chem. Biol. Technol. Agric. 2017, 4, 5. [CrossRef]

13. da Silva, R.R. Bacterial and fungal proteolytic enzymes: Production; catalysis and potential applications. Appl. Biochem. Biotechnol. 2017, 183, 1-19. [CrossRef] [PubMed]

14. da Silva, R.R. Comment on mRNA-Sequencing Analysis Reveals Transcriptional Changes in Root of Maize Seedlings Treated with Two Increasing Concentrations of a New Biostimulant. J. Agric. Food. Chem. 2018, 66, 2061-2062. [CrossRef] [PubMed]

15. Ertani, A.; Francioso, O.; Ferrari, E.; Schiavon, M.; Nardi, S. Spectroscopic-Chemical Fingerprint and Biostimulant Activity of a Protein-Based Product in Solid Form. Molecules 2018, 23, E1031. [CrossRef] [PubMed]

16. Trevisan, S.; Manoli, A.; Ravazzolo, L.; Franceschi, C.; Quaggiotti, S. mRNA-Sequencing Analysis Reveals Transcriptional Changes in Root of Maize Seedlings Treated with Two Increasing Concentrations of a New Biostimulant. J. Agric. Food. Chem. 2017, 65, 9956-9969. [CrossRef]

17. Trevisan, S.; Manoli, A.; Begheldo, M.; Nonis, A.; Enna, M.; Vaccaro, S.; Caporale, G.; Ruperti, B.; Quaggiotti, S. Transcriptome analysis reveals coordinated spatiotemporal regulation of hemoglobin and nitrate reductase in response to nitrate in maize roots. New Phytol. 2011, 192, 338-352. [CrossRef] [PubMed]

18. Trevisan, S.; Begheldo, M.; Nonis, A.; Quaggiotti, S. The miRNA-mediated post-transcriptional regulation of maize response to nitrate. Plant Signal. Behav. 2012, 7, 822-826. [CrossRef] [PubMed]

19. Trevisan, S.; Manoli, A.; Ravazzolo, L.; Botton, A.; Pivato, M.; Masi, A.; Quaggiotti, S. Nitrate sensing by the maize root apex transition zone: A merged transcriptomic and proteomic survey. J. Exp. Bot. 2015, 66, 3699-3715. [CrossRef]

20. Trevisan, S.; Trentin, A.R.; Ghisi, R.; Masi, A.; Quaggiotti, S. Nitrate affects transcriptional regulation of UPBEAT1 and ROS localisation in roots of Zea mays L. Physiol. Plant. 2018. [CrossRef] [PubMed]

21. Quaggiotti, S.; Ruperti, B.; Borsa, P.; Destro, T.; Malagoli, M. Expression of a putative high-affinity $\mathrm{NO}_{3}-$ transporter and of an H+ATPase in relation to whole plant nitrate transport physiology in two maize genotypes differently responsive to low nitrogen availability. J. Exp. Bot. 2003, 54, 1023-1031. [CrossRef] [PubMed]

22. Farooq, M.; Hussain, M.; Wakeel, A.; Siddique, K.H.M. Salt stress in maize: Effects; resistance mechanisms; and management. A review. Agron. Sustain. Dev. 2015, 35, 461-481. [CrossRef]

23. Henry, C.; Bledsoe, S.; Griffiths, C.A.; Paul, M.J.; Kollman, A.; Sakr, S.; Lagrimini, M. Differential role for trehalose metabolism in salt stressed maize. Plant Physiol. 2015, 169, 1072-1089. [CrossRef] [PubMed]

24. Zörb, C.; Mühling, K.H.; Kutschera, U.; Geilfus, C.M. Salinity Stiffens the Epidermal Cell Walls of Salt-Stressed Maize Leaves: Is the Epidermis Growth-Restricting? PLoS ONE 2015, 10, e0118406. [CrossRef]

25. Manoli, A.; Sturaro, A.; Trevisan, S.; Quaggiotti, S.; Nonis, A. Evaluation of candidate reference genes for qPCR in maize. J. Plant Physiol. 2012, 169, 807-815. [CrossRef] [PubMed]

26. Manoli, A.; Begheldo, M.; Genre, A.; Lanfranco, L.; Trevisan, S.; Quaggiotti, S. NO homeostasis is a key regulator of early nitrate perception and root elongation in maize. J. Exp. Bot. 2014, 65, 185-200. [CrossRef] [PubMed]

27. Livak, K.J.; Schmittgen, T.D. Analysis of relative gene expression data using real-time quantitative PCR and the 2- $\Delta \Delta$ CT method. Methods 2001, 25, 402-408. [CrossRef] [PubMed]

28. Bustin, S.A.; Nolan, T. Pitfalls of quantitative real-time reverse-transcription polymerase chain reaction. J. Biomol. Tech. 2004, 15, 155-166. [PubMed]

29. Schaafsma, G. Safety of protein hydrolysates; fractions thereof and bioactive peptides in human nutrition. Eur. J. Clin. Nutr. 2009, 63, 1161-1168. [CrossRef] [PubMed] 
30. du Jardin, P. The Science of Plant Biostimulants-A bibliographic analysis. Ad hoc Study Report to the European Commission DG ENTR 2012. Available online: https://orbi.uliege.be/handle/2268/169257 (accessed on 7 January 2019).

31. Kasparkova, V.; Kolomaznik, K.; Burketova, L.; Sasek, V.; Simek, L. Characterization of low-molecular weight collagen hydrolysates prepared by combination of enzymatic and acid hydrolysis. J. Am. Leather Chem. Assoc. 2009, 104, 46-51.

32. Pecha, J.; Fürst, T.; Kolomaznik, K.; Friebrova, V.; Svoboda, P. Protein biostimulant foliar uptake modeling: The impact of climatic conditions. AIChE J. 2012, 58, 2010-2019. [CrossRef]

33. Baglieri, A.; Cadili, V.; Monterumici, C.M.; Gennari, M.; Tabasso, S.; Montoneri, E.; Nardi, S.; Negre, M. Fertilization of bean plants with tomato plants hydrolysates. Effect on biomass production; chlorophyll content and N assimilation. Sci. Hortic. 2014, 176, 194-199. [CrossRef]

34. Colla, G.; Nardi, S.; Cardarelli, M.; Ertani, A.; Lucini, L.; Canaguier, R.; Rouphael, Y. Protein hydrolysates as biostimulants in horticulture. Sci. Hortic. 2015, 96, 28-38. [CrossRef]

35. Calvo, P.; Nelson, L.; Kloepper, J.W. Agricultural uses of plant biostimulants. Plant Soil. 2014, 383, 3-41. [CrossRef]

36. Yakhin, O.I.; Lubyanov, A.A.; Yakhin, I.A.; Brown, P.H. Biostimulants in plant science: A global perspective. Front. Life Sci. 2017. [CrossRef] [PubMed]

37. Mittler, R. Abiotic stress; the field environment and stress combination. Trends Plant Sci. 2006, 11, 15-19. [CrossRef] [PubMed]

38. Mittler, R.; Blumwald, E. Genetic engineering for modern agriculture: Challenges and perspectives. Annu. Rev. Plant Biol. 2010, 61, 443-462. [CrossRef] [PubMed]

39. Suzuki, N.; Rivero, R.M.; Shulaev, V.; Blumwald, E.; Mittler, R. Abiotic and biotic stress combinations. New Phytol. 2014, 203, 32-43. [CrossRef] [PubMed]

40. Malamy, J.E. Intrinsic and environmental response path- ways that regulate root system architecture. Plant Cell Environ. 2005, 28, 67-77. [CrossRef]

41. Hodge, A.; Berta, G.; Doussan, C.; Merchan, F.; Crespi, M. Plant root growth; architecture and function. Plant Soil 2009, 321, 153-187. [CrossRef]

42. Kong, X.; Liu, G.; Liu, J.; Ding, Z. The Root Transition Zone: A Hot Spot for Signal Crosstalk. Trends Plant Sci. 2018, 23, 403-409. [CrossRef]

43. Alarcon, M.V.; Salguero, J. Transition zone cells reach G2 phase before initiating elongation in maize root apex. Biol. Open 2017, 6, 909-913. [CrossRef]

44. Yang, Z.B.; Geng, X.; He, C.; Zhang, F.; Wang, R.; Horst, W.J.; Ding, Z. TAA1-regulated local auxin biosynthesis in the root-apex transition zone mediates the aluminum-induced inhibition of root growth in Arabidopsis. Plant Cell 2014, 26, 2889-2904. [CrossRef]

45. Baluska, F.; Volkmann, D.; Barlow, P.W. Specialized zones of development in roots: View from the cellular level. Plant Physiol. 1996, 112, 3-4. [CrossRef] [PubMed]

46. Baluska, F.; Mancuso, S.; Volkmann, D.; Barlow, P.W. Root apex transition zone: A signalling-response nexus in the root. Trends Plant Sci. 2010, 15, 402-408. [CrossRef] [PubMed]

47. Baluska, F.; Mancuso, S. Root apex transition zone as oscillatory zone. Front. Plant Sci. 2013, 4, 354. [CrossRef] [PubMed]

48. Colla, G.; Hoagland, L.; Ruzzi, M.; Cardarelli, M.; Bonini, P.; Canaguier, R.; Rouphael, Y. Biostimulant Action of Protein Hydrolysates: Unraveling Their Effects on Plant Physiology and Microbiome. Front. Plant Sci. 2017, 8, 2202. [CrossRef]

49. Lucini, L.; Rouphael, Y.; Cardarelli, M.; Bonini, P.; Baffi, C.; Colla, G. A Vegetal Biopolymer-Based Biostimulant Promoted Root Growth in Melon While Triggering Brassinosteroids and Stress-Related Compounds. Front. Plant Sci. 2018, 9, 472. [CrossRef] [PubMed]

50. Sestili, F.; Rouphael, Y.; Cardarelli, M.; Pucci, A.; Bonini, P.; Canaguier, R.; Colla, G. Protein Hydrolysate Stimulates Growth in Tomato Coupled With N-Dependent Gene Expression Involved in N Assimilation. Front. Plant Sci. 2018, 9, 1233. [CrossRef] 
51. Plett, D.C.; Holtham, L.R.; Okamoto, M.; Garnett, T.P. Nitrate uptake and its regulation in relation to improving nitrogen use efficiency in cereals. Semin. Cell Dev. Biol. 2018, 74, 97-104. [CrossRef] [PubMed]

52. Wang, W.; Xia, M.X.; Chen, J.; Yuan, R.; Deng, F.N.; Shen, F.F. Gene Expression Characteristics and Regulation Mechanisms of Superoxide Dismutase and Its Physiological Roles in Plants under Stress. Biochemistry 2016, 81, 465-480. [CrossRef] [PubMed] 